\title{
Supporting Information \\ For \\ Dinuclear Oxovanadium(IV) Thiolate Complexes with Ferromagnetically Coupled Interaction between Vanadium Centers
}

Synthesis of $\left[\mathbf{N}\left(\mathbf{C}_{\mathbf{5}} \mathbf{H}_{11}\right)_{4}\right]_{2}[\mathrm{VOL1}]_{\mathbf{2}}(\mathbf{1})$ : A methanol solution of $\mathrm{VO}(\mathrm{acac})_{2}(0.143 \mathrm{~g}, 0.54 \mathrm{mmol})$ was added to a methanol solution of $\mathrm{H}_{3}\left[{ }^{\mathrm{Me}} \mathrm{SiS} 3\right](0.200 \mathrm{~g}, 0.54 \mathrm{mmol}){ }^{1}$ and $\mathrm{CH}_{3} \mathrm{ONa}(0.088 \mathrm{~g}, 1.63 \mathrm{mmol})$ to generate a brown solution. The reaction mixture changed to green color after stirring for 30 mins. The solution was concentrated and layered with $\left[\mathrm{N}\left(\mathrm{C}_{5} \mathrm{H}_{11}\right)_{4}\right] \mathrm{Br}(0.205 \mathrm{~g}, 0.54 \mathrm{mmol})$ in methanol to give a green crystalline solid of 1 [0.130 g, 0.10 mmol, ca. $38 \%$ based on $\mathrm{VO}(\mathrm{acac})_{2}$ ]. Anal. Calcd for $\mathrm{C}_{66} \mathrm{H}_{110} \mathrm{~N}_{2} \mathrm{O}_{4} \mathrm{~S}_{4} \mathrm{Si}_{2} \mathrm{~V}_{2}: \mathrm{C}_{\text {, }}$ 61.84; H, 8.65; N, 2.19; S, 10.01. Found: C, 60.98; H, 8.68; N, 2.11; S, 9.87. UV/Vis in $\mathrm{CH}_{2} \mathrm{Cl}_{2}(\lambda, \mathrm{nm} ; \varepsilon$, $\left.\mathrm{M}^{-1} \mathrm{~cm}^{-1}\right): 230\left(1.21 \times 10^{6}\right), 685\left(1.30 \times 10^{2}\right) . \quad \mathrm{IR}\left(\mathrm{KBr}, \mathrm{cm}^{-1}\right): v_{\mathrm{V}=\mathrm{O}}=985$.

Synthesis for $\left[\mathbf{N}\left(\mathbf{C}_{\mathbf{4}} \mathbf{H}_{\mathbf{9}}\right)_{4}\right]\left[(\mathrm{VOL} 2)_{2}\left(\boldsymbol{\mu}-\mathbf{O C H}_{3}\right)\right](\mathbf{2})$ : An $i$-PrOH solution of $\mathrm{VO}(i \text {-PrO })_{3}(0.074 \mathrm{~g}, 0.31 \mathrm{mmol})^{2}$ was added to a methanol solution of $\mathrm{H}_{2}\left[{ }^{\mathrm{Ph}} \mathrm{PS} 2\right](0.100 \mathrm{~g}, 0.31 \mathrm{mmol})^{1}$ and $\mathrm{CH}_{3} \mathrm{ONa}(0.050 \mathrm{~g}, 0.93 \mathrm{mmol})$ to generate a deep green solution. The reaction mixture changed to light green color after stirring for 30 mins.

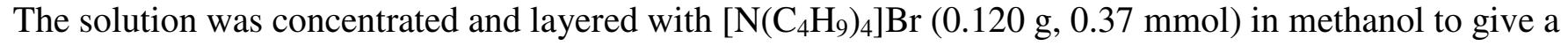
green crystalline solid of $2 \cdot \mathrm{H}_{2} \mathrm{O}$ [0.111 g, $0.10 \mathrm{mmol}$, ca. $65 \%$ based on $\left.\mathrm{VO}(i-\mathrm{PrO})_{3}\right]$. Anal. Calcd for 2 . $\mathrm{H}_{2} \mathrm{O}\left(\mathrm{C}_{53} \mathrm{H}_{67} \mathrm{NO}_{6} \mathrm{~S}_{4} \mathrm{P}_{2} \mathrm{~V}_{2}\right)$ : C, 57.55; H, 6.10; N, 1.27; S, 11.60. Found: C, 56.63; H, 6.14; N, 1.23; S, 11.14.

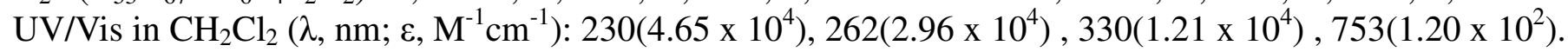
$\operatorname{IR}\left(\mathrm{KBr}, \mathrm{cm}^{-1}\right): v_{\mathrm{V}=\mathrm{O}}=961$.

1. Block, E.; Eswarakrishnan, V.; Gernon, M. J. Am. Chem. Soc. 1989, 111, 658.

2. Hillerns, H.; Rehder, D. Chem. Ber. 1991, 2249-2254. 
Figure S1. Packing diagrams of compounds 1 (top) and 2 (bottom). The shortest distance between phenyl rings of two molecules is $4.65 \AA$, indicating the presence of an intermolecular $\pi$ - $\pi$ interaction between molecules. However, the intermolecular interaction in compound $\mathbf{2}$ is not so pronounced as we observed in the packing diagram. The shortest distance between phenyl rings of different molecules is $6.32 \AA$ in 2 .
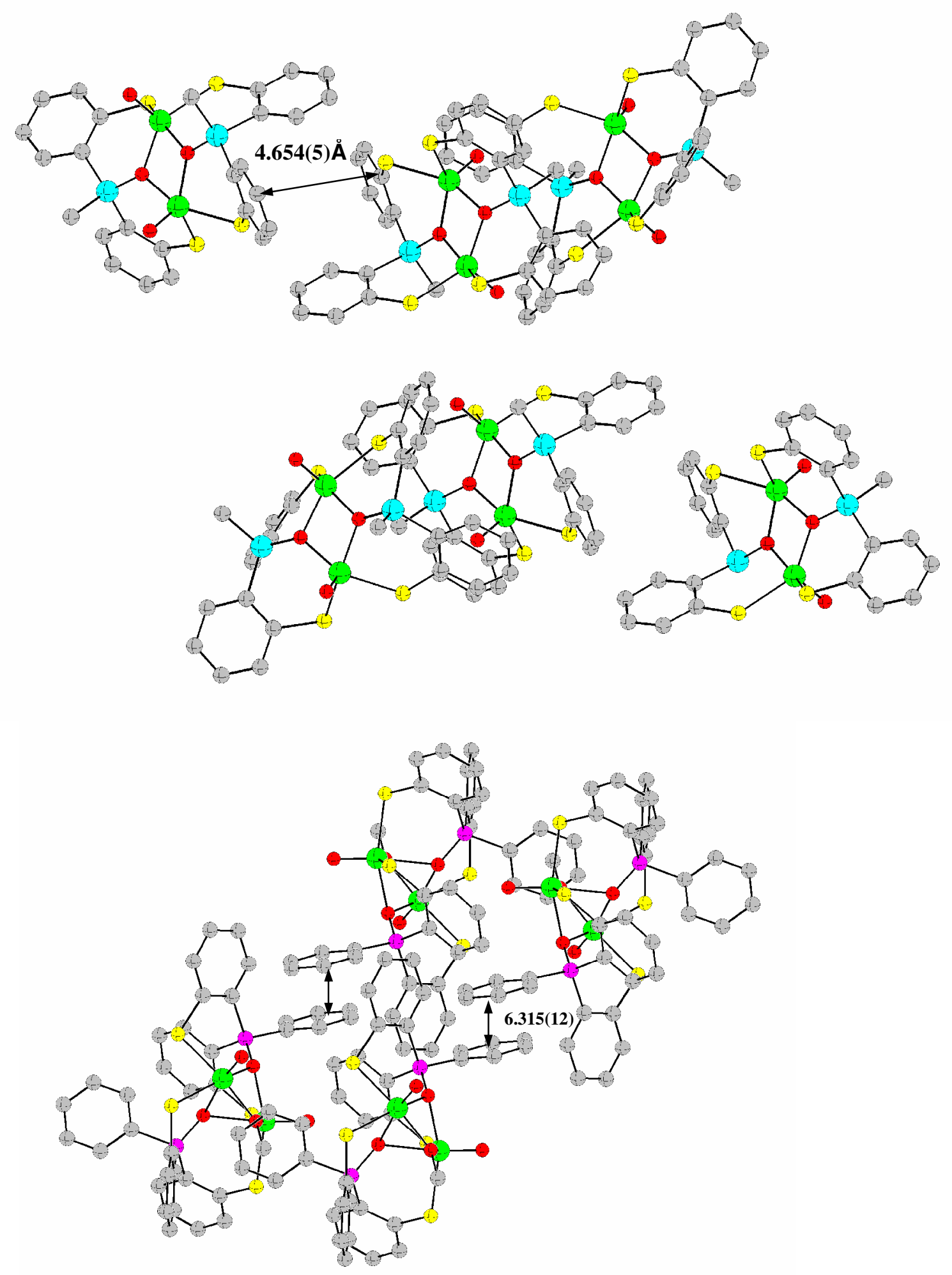
Figure S2. Magnetization for compound 1 (top) and compound 2 (bottom), in the form of M/N $\beta$, at 2-5K and in the filed range of compound $\mathbf{1}$ are 0.05-7 $\mathrm{T}$ and compound $\mathbf{2}$ are 0.1-7 T.
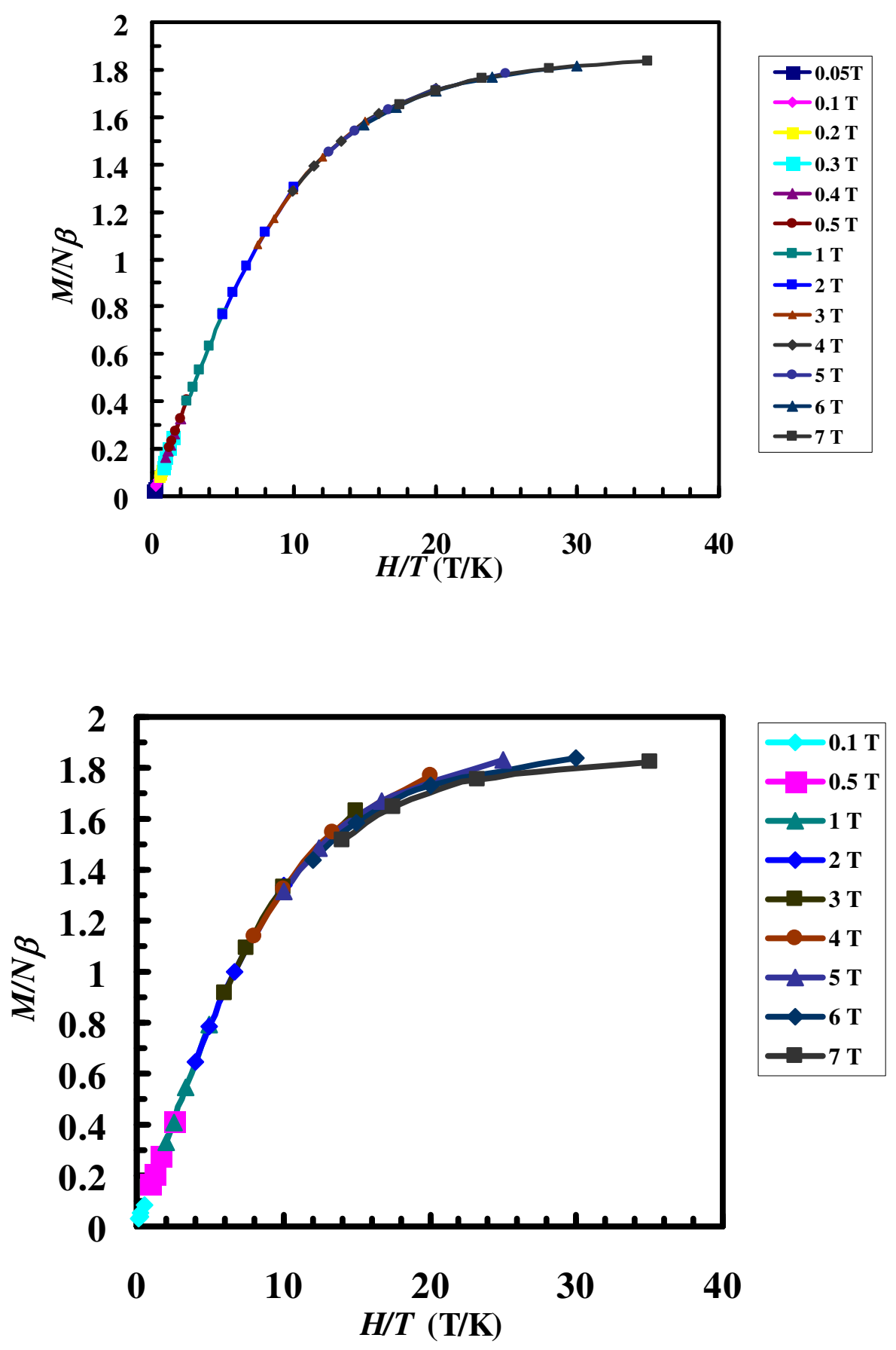